\title{
Generation and verification of three-dimensional network of fractured rock masses stochastic discontinuities based on digitalization
}

\author{
Liang Guo $\cdot$ Xiaozhao Li $\cdot$ Yangyi Zhou • \\ Yangsong Zhang
}

Received: 21 September 2014/ Accepted: 10 February 2015/Published online: 28 February 2015

(C) The Author(s) 2015. This article is published with open access at Springerlink.com

\begin{abstract}
Accuracy of seepage simulation in rock masses is directly influenced by related geometrical parameters of DFN (discrete fracture network) models. In this paper a well-planned investigation of rock mass discontinuities was conducted on well-exposed outcrops in Beishan (Gansu province), one of the main candidate sites for the Chinese high-level radioactive waste repository using digital techniques, e.g. global positioning system, close range digital photogrammetry and geographical information system. This allows for very efficient collection of large volumes of data, over 10,000 discontinuities were obtained at the study site (Jijicao block), based on statistical parameters two homogeneities were identified, and the dominant sets were also delineated, which suggested that two sets exist in homogeneity I, while three sets in homogeneity II. In homogeneity I, The optimal fracture diameter probability distributions of both sets were lognormal. Three-dimensional stochastic DFN models were established for both homogeneities based on stochastic process as well as statistical parameters. The reliability of the model was validated by both graphical and numerical methods. Results showed that: digital techniques used in this study can overcome the problem of sample size and precision
\end{abstract}

L. Guo $(\bowtie) \cdot$ X. Li

School of Earth Sciences and Engineering, Nanjing University, Nanjing, Jiangsu 210046, China

e-mail: guoliang688@126.com

Y. Zhou

Institute of Rock and Soil Mechanics, Chinese Academy of Sciences, Wuhan 430071, China

Y. Zhang

Department of Civil Engineering, Nanjing University of Science and Technology, Nanjing 210094, China restriction posed by traditional methods, which leads to a more effective application of DFN model, and are thus suitable for tasks such as detailed mapping of rock masses in large area. It is believed that this verified DFN model is more appropriate for subsequent calculations of mechanical properties and seepage of fractured rock masses.

Keywords Beishan of Gansu province · Fractured rock masses - Discontinuity network - Stochastic simulation . Verification · Digitalization

\section{Introduction}

The discontinuous, inhomogeneous and anisotropic nature of the rock mass is mainly attributed to its internal discontinuities. In the heterogeneous rock mass subjected to multi-stage, multi-directional stress field usually form the discontinuities which are distributed randomly and irregularly, as a result study involving the geological discontinuities is generally under the framework of statistics and probability theory (e.g., Watson and Irving 1957; Kiraly 1969; Oda 1980; Einstein and Baecher 1983; Baecher 1983), with the aim of investigating the characteristics of their orientation, size, spacing, density, shape and spatial distribution (e.g., Snow 1970; Watkins 1971; Shanley and Mahtab 1976; Cruden 1977; Pahl 1981; Priest and Hudson 1981; Oda 1982; Mahtab and Yegulap 1984). Based on the parameters measured on the outcrop, a detailed statistical analysis is conducted, followed by the geometric model generated using Monte-Carlo simulation. Mechanical and hydraulic research is then carried out based on this model (Müller et al. 2010). Systematic investigations on the threedimensional discontinuities network were conducted (e.g., Robinson 1983; Kulatilake et al. 1984, 1985, 1990; 
Dershowitz et al. 1988; Xu and Peter Xu and Peter 2010) and the techniques developed were successfully extended to the field of rock mechanics (e.g., Einstein et al. 1983; Sen and Kazi 1984; Kulatilake et al. 1993).

Considering the structure of the fractured rock mass Lei and Yuan (1989) proposed a two-dimensional stochastic model using joint midpoint equal probability method, which is the basis for the subsequent analysis of rock mechanics; Xu (1992) established a comprehensive numerical model of jointed rock mass and conducted calculation of rock blocks, fracture network and fluid flow, Using three-dimensional network model, Zhu (1992) investigated constitutive relationship of the network system with non-transect joints, and further analysed the influencing factors of the elastic deformation of rock mass; Chen et al. $(1995,2001)$ carried out detailed studies on the stochastic discontinuities network model after parameters (e.g., orientation, trace length, spacing, etc.) bias correction; The other promising applications of the network model were investigated by Jia et al. (2002), including the evaluation of rock mass quality, isolated body search, evaluation of joint network connectivity, estimation of the rock mass strength and permeability, joint failure judgment and so forth; Wang et al. (2004) compared the cross-sectional view of the stochastic simulation model with that of the measured outcrop, in an efforts to verify the validity of the simulation. However, the quantitative descriptions of discontinuity features in practical applications are mainly obtained by traditional manual measurement, the sample size and accuracy required by the parameter study are quite limited, significant bias cannot be avoided if too much subjectivity is involved in the statistical process ( $\mathrm{Li}$ et al. 2011), and the practical need cannot always be met by the model reliability.

Statistical samples obtained based on global positioning system (GPS) and geographical information system (GIS), both in terms of quantity and accuracy, were significantly improved compared with traditional methods (e.g., scan line or window sampling). The whole group of discontinuities in a region can theoretically be sampled by the digital techniques (Huang et al. 2014; Kissinger et al. 2013). The advantage is that the bias of subjectively selecting outcrops can be minimized by complete sampling strategy. It is possible to conduct a detailed discontinuity investigation in a wide large region (Koike et al. 2011; Tenzer et al. 2010). In view of our group has embarked on an integrated research program, whose main goal is to build up a proper stochastic discontinuity network model for Beishan (Gansu province), one of the main candidate sites for the Chinese HLW (high-level radioactive waste) repository.

\section{Acquisition and pretreatment of data}

\section{Description of the study site}

The study site is located in Jijicao block in Beishan (Gansu province), which is one of the main candidate sites, for Chinese HLW repository. Rock is well-exposed on outcrops in this $12 \mathrm{~km}^{2}$ region. The main lithology of this area is biotite monzonitic granite. Tectonic deformation in this area is characterized by brittle fractures and joints, together with less developed ductile shear deformation. Since the Indosinian-Yanshanian period, tectonic stress field has been dominated by left-lateral strike slip so that inside this area low-angle fractures are in continuous development. The EW direction boundary faults were thus cut and offset by the NE direction fault. Long fractures and fracture zones are mainly characterized by steep dip angle. The discontinuities location and relationship with faults are shown in Fig. 1. The attribute properties of measurement areas $(\mathrm{A} \sim \mathrm{N}, \mathrm{P} \sim \mathrm{S}$ in Fig. 1$)$ as shown in Table 1 and the statistical results of discontinuities geometrical properties are shown in Table 2.

\section{Methods}

To implement fast and efficient digitization acquisition of the discontinuity geometrical properties, such as trace length, persistence, spacing, orientation, aperture and roughness, high-precision GPS-RTK (Real Time Kinematic) is adopted for accurate positioning and data collection (Fig. 2), the real-time kinematic carrier phase differential method is used in this system to position objects, the precision of position data obtained from satellite positioning system can thus be improved to centimeter level, together with compass (detailed measurement), digital close range photogrammetry (for the purpose of auxiliary measurement and orientation checking) and digital camera (micro-focus photographing). More than ten thousands of discontinuities distributed in 18 areas (Fig. 1) are first numbered, measured, and picture-taking with placement of a steel ruler close to the discontinuity, discontinuity parameters can be obtained after post-processing of the measured data and photos. More specifically, orientation data is obtained from compass measurement and digital close range photogrammetry, trace length, persistence and spacing are obtained from measured discontinuity coordinates. Aperture and roughness data are extracted from micro-focus photos by programs. An illustration of the processing procedure is shown in Fig. 3. 
Fig. 1 Discontinuities measuring location and relationship with faults in Jijicao block $(\mathrm{A} \sim \mathrm{N}, \mathrm{P} \sim \mathrm{S}$ are measurement areas, F1 F7 are major faults, surface discernable lengths of $\mathrm{F} 1 \sim \mathrm{F} 6$ are over $1 \mathrm{~km}$, while length of F7 is less than $1 \mathrm{~km}$ )

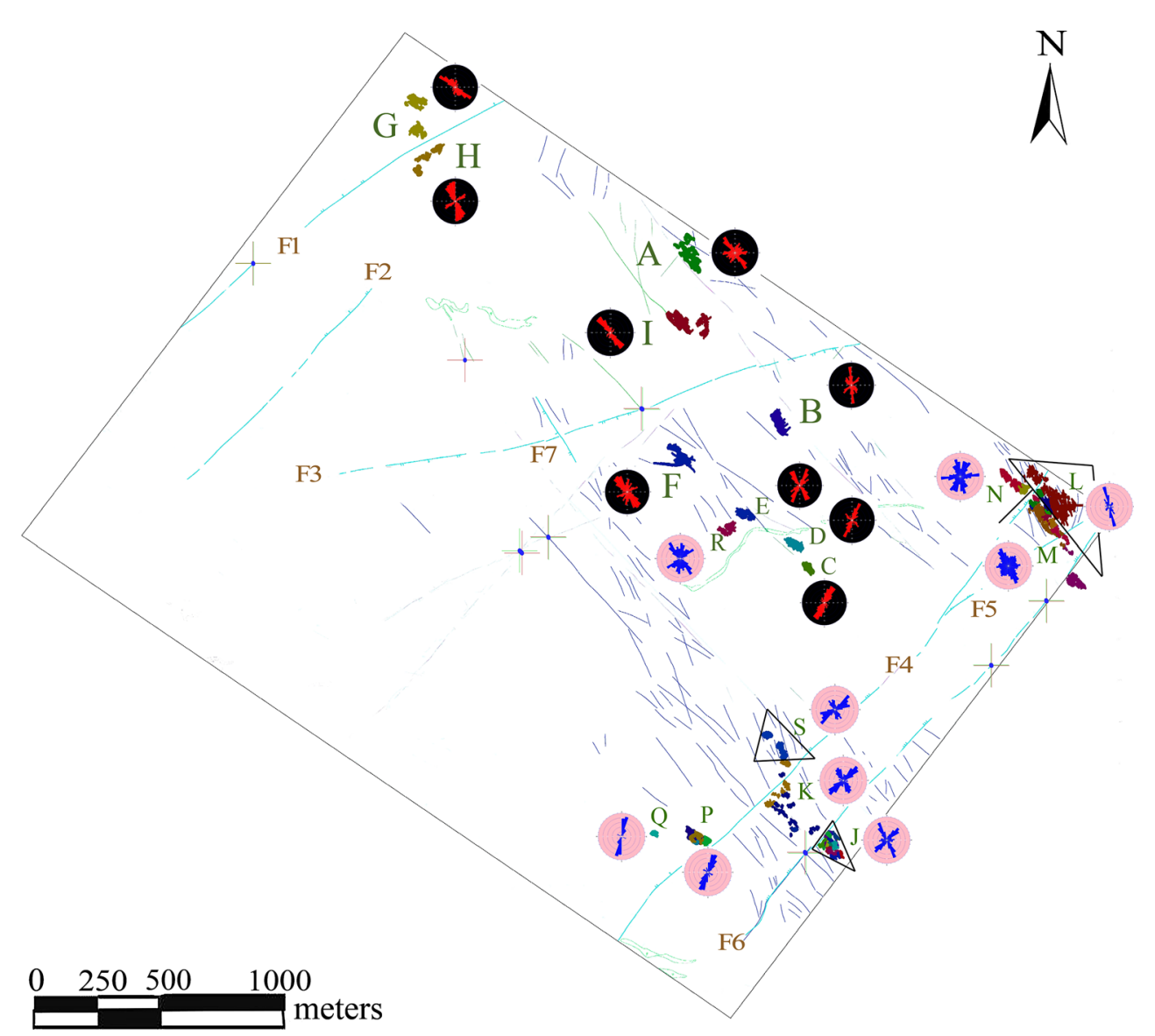

\begin{tabular}{lllll}
\hline Areas & Center coordinates & Homogeneity & $\begin{array}{l}\text { Discontinuity number } \\
\text { (amount) }\end{array}$ & $\begin{array}{l}\text { Number of dominant } \\
\text { set (amount) }\end{array}$ \\
\hline A & N4046 $16^{\prime \prime} / \mathrm{E} 97^{\circ} 29^{\prime} 7^{\prime \prime}$ & - & 945 & 3 \\
$\mathrm{~B}$ & $\mathrm{~N} 40^{\circ} 45^{\prime} 50^{\prime \prime} / \mathrm{E} 97^{\circ} 29^{\prime} 23^{\prime \prime}$ & - & 699 & 4 \\
$\mathrm{C}$ & $\mathrm{N} 40^{\circ} 45^{\prime} 25^{\prime \prime} / \mathrm{E} 97^{\circ} 29^{\prime} 31^{\prime \prime}$ & $\mathrm{I}$ & 561 & 2 \\
$\mathrm{D}$ & $\mathrm{N} 40^{\circ} 45^{\prime} 31^{\prime \prime} / \mathrm{E} 97^{\circ} 29^{\prime} 26^{\prime \prime}$ & $\mathrm{I}$ & 485 & 2 \\
$\mathrm{E}$ & $\mathrm{N} 40^{\circ} 45^{\prime} 35^{\prime \prime} / \mathrm{E} 97^{\circ} 29^{\prime} 18^{\prime \prime}$ & $\mathrm{I}$ & 500 & 2 \\
$\mathrm{~F}$ & $\mathrm{~N} 40^{\circ} 45^{\prime} 43^{\prime \prime} / \mathrm{E} 97^{\circ} 29^{\prime} 5^{\prime \prime}$ & - & 572 & 3 \\
$\mathrm{G}$ & $\mathrm{N} 40^{\circ} 46^{\prime} 40^{\prime \prime} / \mathrm{E} 97^{\circ} 28^{\prime} 12^{\prime \prime}$ & $\mathrm{II}$ & 674 & 4 \\
$\mathrm{H}$ & $\mathrm{N} 40^{\circ} 46^{\prime} 32^{\prime \prime} / \mathrm{E} 97^{\circ} 28^{\prime} 18^{\prime \prime}$ & $\mathrm{II}$ & 263 & 2 \\
$\mathrm{I}$ & $\mathrm{N} 40^{\circ} 46^{\prime} 6^{\prime \prime} / \mathrm{E} 97^{\circ} 29^{\prime} 4^{\prime \prime}$ & - & 1405 & 4 \\
$\mathrm{~J}$ & $\mathrm{~N} 40^{\circ} 44^{\prime} 43^{\prime \prime} / \mathrm{E} 97^{\circ} 29^{\prime} 32^{\prime \prime}$ & - & 537 & 3 \\
$\mathrm{~K}$ & $\mathrm{~N} 40^{\circ} 44^{\prime} 49^{\prime \prime} / \mathrm{E} 97^{\circ} 29^{\prime} 23^{\prime \prime}$ & - & 488 & 3 \\
$\mathrm{~L}$ & $\mathrm{~N} 40^{\circ} 45^{\prime} 38^{\prime \prime} / \mathrm{E} 97^{\circ} 30^{\prime} 19^{\prime \prime}$ & - & 200 & 2 \\
$\mathrm{M}$ & $\mathrm{N} 40^{\circ} 45^{\prime} 32^{\prime \prime} / \mathrm{E} 97^{\circ} 30^{\prime} 17^{\prime \prime}$ & - & 1340 & 3 \\
$\mathrm{~N}$ & $\mathrm{~N} 40^{\circ} 45^{\prime} 39^{\prime \prime} / \mathrm{E} 97^{\circ} 30^{\prime} 11^{\prime \prime}$ & $\mathrm{I}$ & 677 & 4 \\
$\mathrm{P}$ & $\mathrm{N} 40^{\circ} 44^{\prime} 43^{\prime \prime} / \mathrm{E} 97^{\circ} 29^{\prime} 11^{\prime \prime}$ & $\mathrm{I}$ & 1281 & 2 \\
$\mathrm{Q}$ & $\mathrm{N} 40^{\circ} 44^{\prime} 45^{\prime \prime} / \mathrm{E} 97^{\circ} 28^{\prime} 59^{\prime \prime}$ & $\mathrm{I}$ & 138 & 3 \\
$\mathrm{R}$ & $\mathrm{N} 40^{\circ} 45^{\prime} 32^{\prime \prime} / \mathrm{E} 97^{\circ} 29^{\prime} 14^{\prime \prime}$ & $\mathrm{I}$ & 346 & 3 \\
$\mathrm{~S}$ & $\mathrm{~N} 40^{\circ} 44^{\prime} 58^{\prime \prime} / \mathrm{E} 97^{\circ} 29^{\prime} 25^{\prime \prime}$ & $\mathrm{I}$ & 580 & 2 \\
\hline
\end{tabular}

Table 1 Attribute properties of measurement areas 
Table 2 Statistics and distribution functions of discontinuities geometrical properties

\begin{tabular}{|c|c|c|c|c|c|c|}
\hline \multirow[t]{2}{*}{ Areas } & \multirow[t]{2}{*}{ Dominant set } & \multicolumn{2}{|l|}{ Center orientations } & \multicolumn{3}{|l|}{ Trace length } \\
\hline & & Dip direction $\left(^{\circ}\right)$ & Dip angle $\left(^{\circ}\right)$ & Distribution type & Mean (m) & Variance $\left(\mathrm{m}^{2}\right)$ \\
\hline \multirow[t]{3}{*}{ A } & 1 & 359.1 & 58.5 & Lognormal & 2.143 & 2.056 \\
\hline & 2 & 232.6 & 66.6 & Lognormal & 3.272 & 2.134 \\
\hline & 3 & 297.9 & 64.5 & Lognormal & 3.135 & 2.954 \\
\hline \multirow[t]{4}{*}{ B } & 1 & 84.2 & 60.0 & Lognormal & 2.225 & 2.257 \\
\hline & 2 & 315.6 & 65.9 & Lognormal & 2.034 & 2.755 \\
\hline & 3 & 31.5 & 62.1 & Lognormal & 2.126 & 3.165 \\
\hline & 4 & 229.5 & 60.9 & Lognormal & 2.235 & 2.076 \\
\hline \multirow[t]{2}{*}{$\mathrm{C}$} & 1 & 51.1 & 80.9 & Lognormal & 1.732 & 1.348 \\
\hline & 2 & 125.2 & 75.5 & Lognormal & 2.098 & 2.962 \\
\hline \multirow[t]{2}{*}{$\mathrm{D}$} & 1 & 39.5 & 78.9 & Lognormal & 1.892 & 2.564 \\
\hline & 2 & 286.1 & 73.4 & Lognormal & 2.137 & 2.753 \\
\hline \multirow[t]{2}{*}{ E } & 1 & 53.8 & 83.1 & Lognormal & 1.826 & 2.316 \\
\hline & 2 & 308.0 & 77.1 & Lognormal & 1.652 & 2.278 \\
\hline \multirow[t]{3}{*}{$\mathrm{F}$} & 1 & 326.9 & 73.4 & Exponential & 1.687 & 2.432 \\
\hline & 2 & 271.5 & 79.2 & Lognormal & 2.125 & 2.917 \\
\hline & 3 & 46.8 & 83.5 & Lognormal & 1.437 & 2.259 \\
\hline \multirow[t]{3}{*}{$\mathrm{G}$} & 1 & 32.6 & 70.9 & Gamma & 2.132 & 3.136 \\
\hline & 2 & 225.3 & 73.2 & Gamma & 2.323 & 2.392 \\
\hline & 3 & 129.2 & 70.2 & Gamma & 2.021 & 3.764 \\
\hline \multirow[t]{3}{*}{$\mathrm{H}$} & 1 & 246.3 & 76.0 & Lognormal & 3.325 & 2.357 \\
\hline & 2 & 327.2 & 71.8 & Lognormal & 3.238 & 2.562 \\
\hline & 3 & 267.6 & 87.6 & Lognormal & 2.396 & 1.743 \\
\hline \multirow[t]{4}{*}{ I } & 1 & 275.6 & 84.7 & Lognormal & 1.532 & 2.368 \\
\hline & 2 & 325.9 & 87.3 & Lognormal & 1.587 & 2.426 \\
\hline & 3 & 230.0 & 71.8 & Gamma & 2.264 & 2.492 \\
\hline & 4 & 53.7 & 71.3 & Lognormal & 2.341 & 1.875 \\
\hline
\end{tabular}

\section{Sampling bias correction}

The intersect frequency of the discontinuities and the outcrop often changes with the relative space position, therefore the measured frequency is not its actual frequency and the sampling bias arises. Besides, the transect (intersect) and length sampling bias are usually introduced into trace length measurements. Specifically, the length sampling bias is induced by the larger sampling chance of longer traces than the shorter ones. The sampling bias corrections should therefore be carried out with respect to the measured data before the statistical analysis.

The outcrop frequency of discontinuities which are nearly parallel with the outcrop is apparently different from the actual frequency within the rock mass. The difference is controlled by the angle between discontinuities and outcrop. The larger the angle is, the closer the exposure frequency to the true frequency is. The correction principle of the orientation bias is based on determining the correction factor or weight coefficient which is formulated by the angle between discontinuities and outcrop. The amount of the discontinuities whose outcrop frequency is smaller than the actual frequency is corrected by the correction factor (Zhou 2013).

Classical Terzaghi correction method (Terzaghi 1965) is applied in this paper and the correction factor (Priest 1993) as the following expression:

$$
\begin{aligned}
\mathrm{TCF} & =\frac{1}{\cos \delta} \\
\cos \delta & =\left|\cos \left(\alpha_{n}-\alpha_{s}\right) \cos \beta_{n} \cos \beta_{s}+\sin \beta_{n} \sin \beta_{s}\right|
\end{aligned}
$$

where TCF is the correction coefficient used in the scanline sampling, $\delta$ is the acute angle between the discontinuities normal and the sampling line, $\alpha_{n}, \beta_{n}$ are the trend and plunge of discontinuities normal vector, $\alpha_{\mathrm{s}}, \beta_{s}$ are the trend and plunge of the sampling line. The spatial relationship between the discontinuity, horizontal plane and rock face are shown in Fig. 4.

The actual correction effect of an example (data obtained in E partition) is shown in Fig. 5. Corrected results show that an obvious frequency difference exists between joints inside rock mass and the ones exposed 

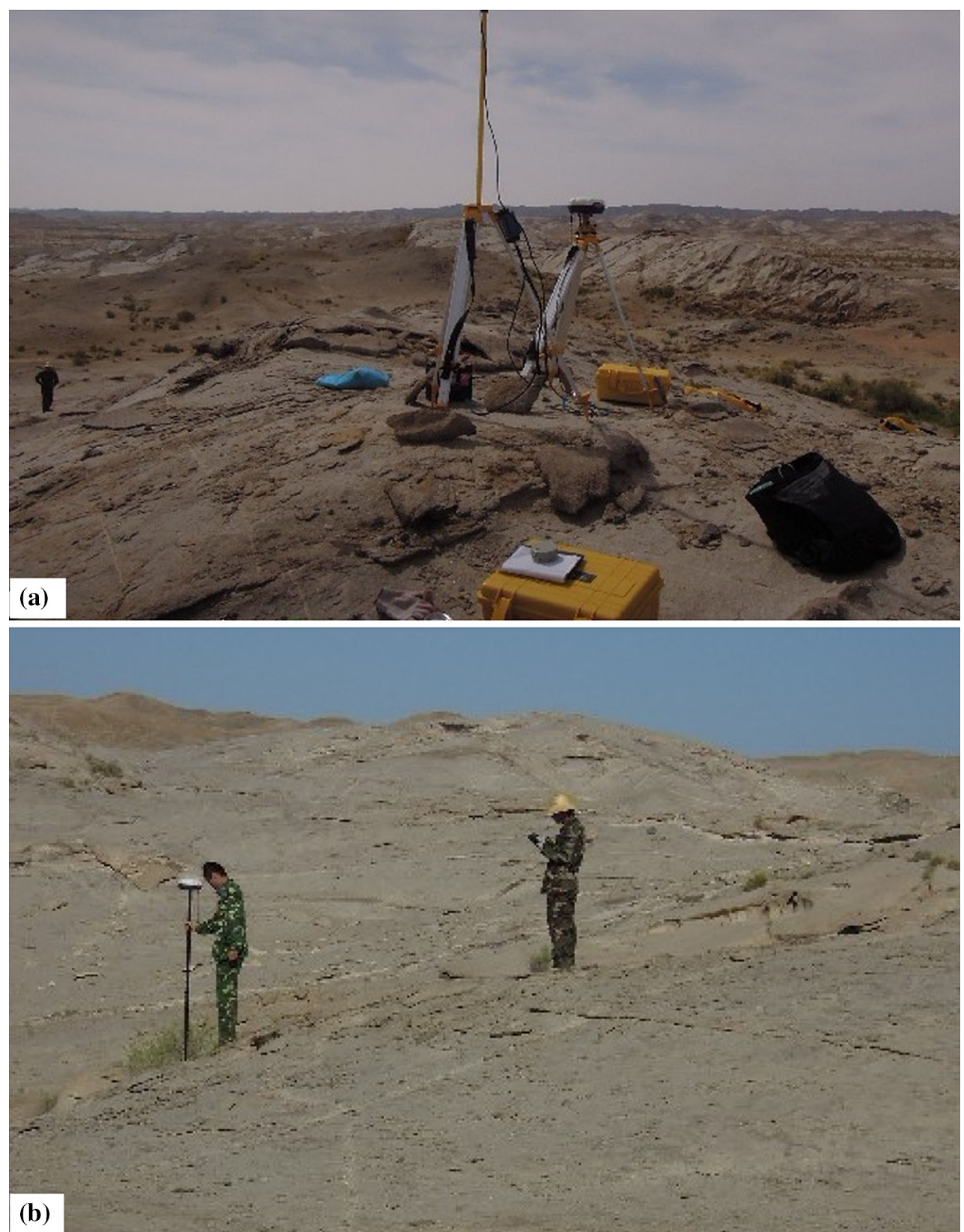

Fig. 2 Measurement of discontinuity in study site by GPS-RTK. a Base station. b Mobile station

on outcrops, when joint is sub-parallel to the outcrop. A considerable large bias may be induced if correction process is neglected. The proposed criterion is that orientation frequency correction should be conducted when the dip angle is relatively small, usually less than $20^{\circ}$.

The orientation distribution function for each set is necessary for trace length bias correction. Unfortunately, these functions cannot be anticipated in this stage therefore the trace length bias corrections are not conducted.

\section{Digitalization processing of data}

Partition of homogeneity

Spatial distribution of discontinuities in the rock mass is always inhomogeneous. More specifically, this heterogeneity means that hydrologic, geologic and mechanical properties of the rock mass vary from one unit to another. Therefore, it is necessary to determine the homogeneity with similar discontinuities structure and parameters before 

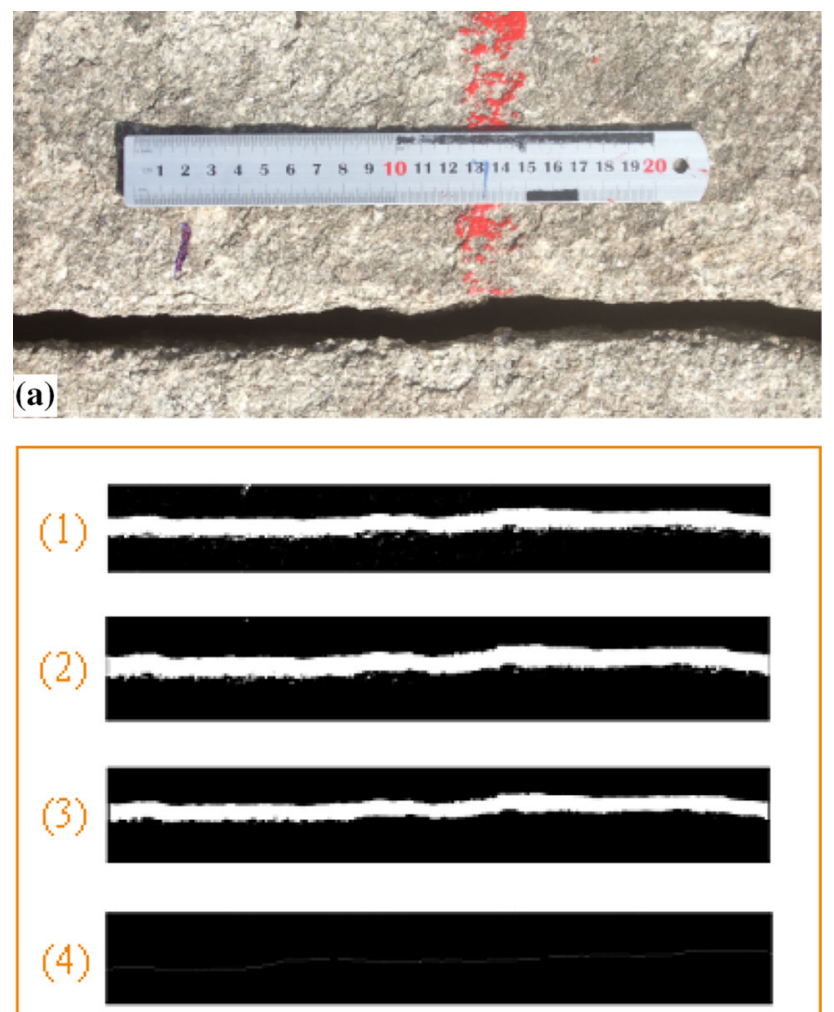

(b)

Fig. 3 Digitalization processing for roughness and aperture of discontinuity. a Micro-focus photos are taken with placement of a steel ruler next to the discontinuity. b Digitalization processing procedure 1 threshold segmentation 2 denoising 3 morphological algorithm, 4 extract skeleton line of the discontinuity

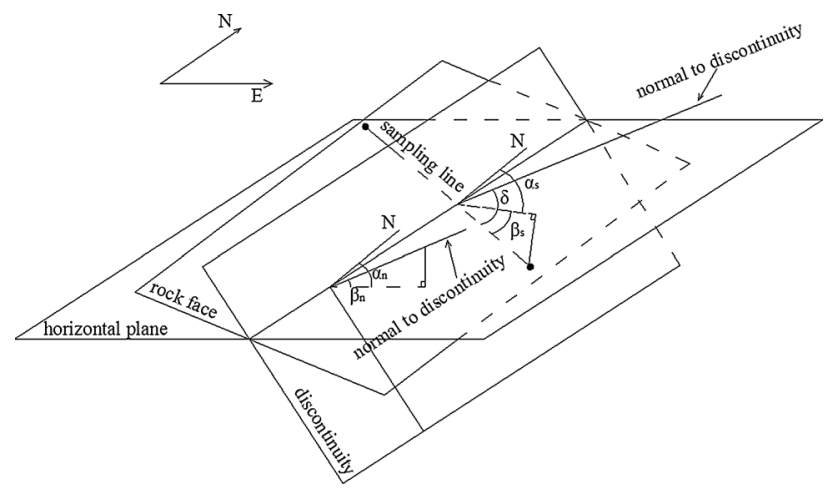

Fig. 4 Diagram illustrating the spatial relationship between discontinuity, horizontal plane and rock face

simulation, to carry out subsequent statistics and modeling, as well as the mechanics and hydraulics research, based on a reasonable partition scheme. Miller (1983) successfully divided the rock mass structure into different homogeneities based on the orientation parameters. The modified Miller method adopted by Kulatilake et al. (1996) also achieved appealing results. An attempt were made by the authors
(Guo et al. 2013; Li et al. 2014) to obtain the homogeneities of Jijicao block using the more appropriate Miller method (34-patch large area method) after comparing between different methods. Two homogeneities (CDERSPQN belong to partition I, GH belong to partition II) were obtained after excluding individual interference data. $\mathrm{G}$ and $\mathrm{H}$ areas around F1 lied in the northern, CDERSPQN across F3 lied in the middle of F2 and F4 (shown in Fig. 1). Jijicao block mainly consists of biotite monzonitic granite. The rock mass has suffered two tectonic movements after the last episode of magma intrusion. Seven faults with length in the order of kilometer were identified in the block which was mainly controlled by the NE direction faults. These NE direction faults were characterized by tensile and tense-shearing properties, accompanied by EW direction compressive and compress-shearing fractures. All of the fractures mentioned above were formed roughly in the same time (late Hercynian). Based on this type of structure characteristics together with the regional tectonic history, a preliminary conclusion can be drawn that the whole piece of rock mass generally shows a relatively high degree of homogeneity, however, specific local areas may be influenced by faults, and thus the degree of homogeneity becomes lower. For example: the longest left-lateral strike slip fault (F3) has the most considerable impact on the overall homogeneity of the block and it is difficult to clearly identify the homogeneity of rock mass near the fault. The theoretical results also confirmed the overall empirical judgment quite well (CDERSPQN belong to partition I with the strongest homogeneity; GH belong to partition II with less obvious homogeneity; F3 fault has a great effect on areas of F and I that lead to the significant difference between them).

\section{Identification of dominant discontinuity sets}

Fuzzy clustering method (Hammah and Curran 1998) is used to identify dominant discontinuity sets in homogeneity I and II. This method achieves the optimal division of discontinuity sets by minimizing the objective function. First of all, according to the data characteristics the objective function is defined (this function usually consists of the sum of a certain distance between orientation data, and the orientation distance is represented by the sine value of normal vector angle between two discontinuities), followed by the determination of the fuzzy variables which represent membership degree, and then according to fuzzy variable values (membership degree) the category to which each data belongs is determined. Based on the above algorithm, author himself has written a fuzzy clustering grouping program to handle the measured orientation data. Furthermore, an improvement was added to the original algorithm to better deal with the orientation data with similar membership degree among different sets. 
Fig. 5 Comparison of correct sampling bias on discontinuities orientation (Red before correction; Blue after correction)

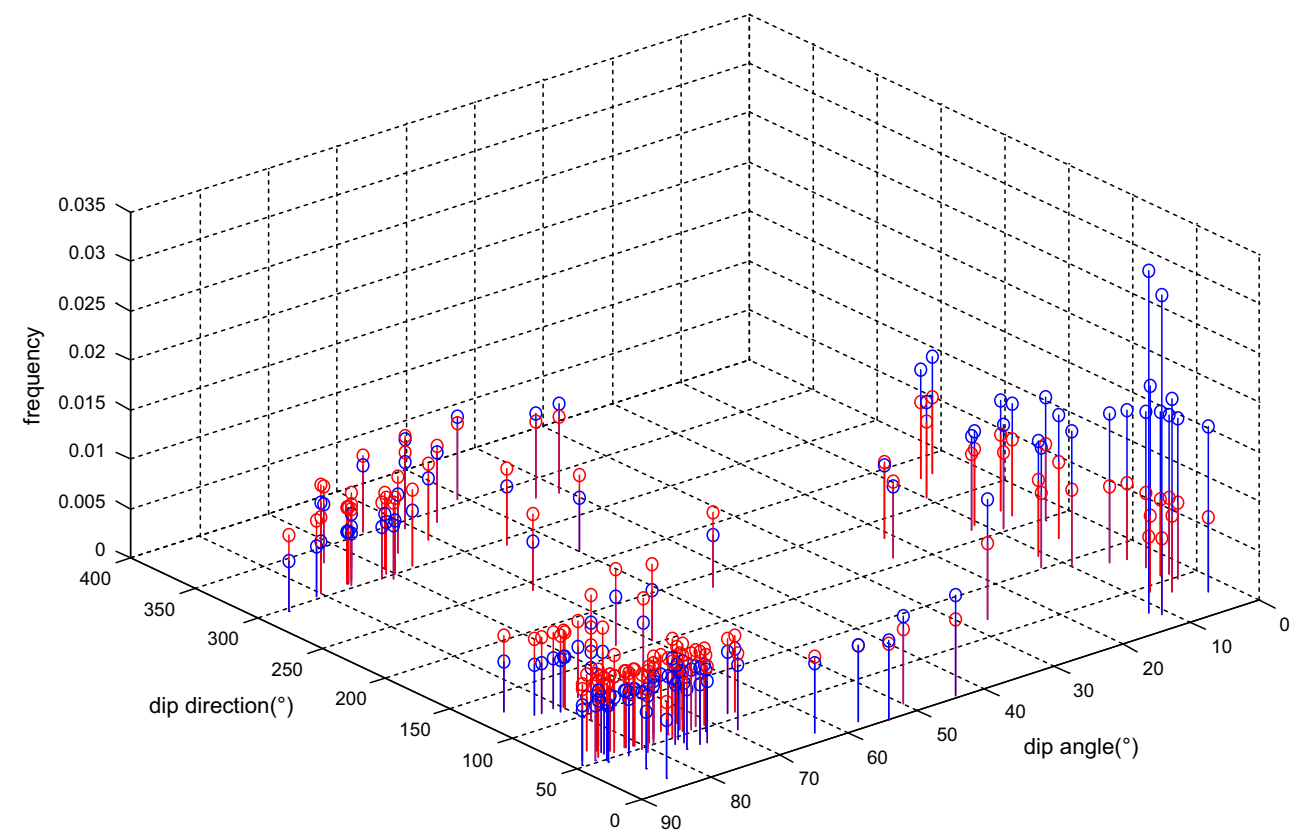

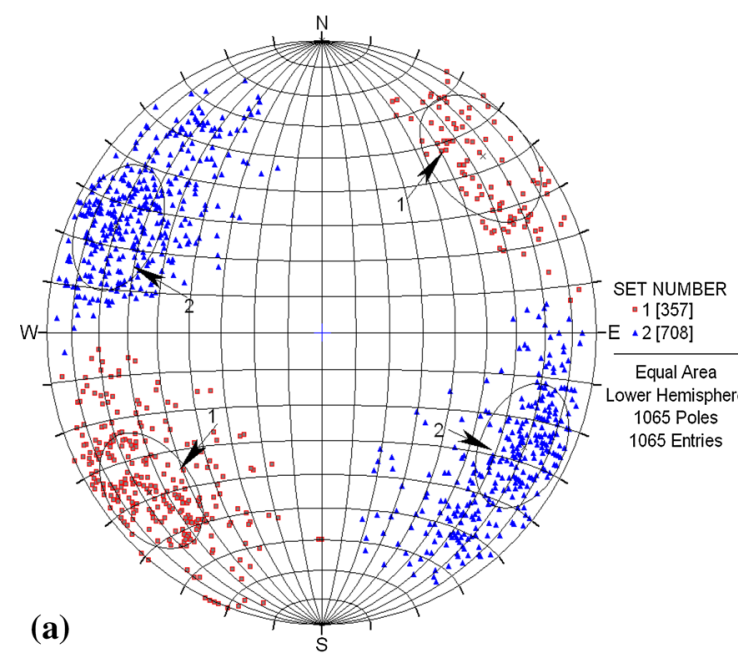

(b)

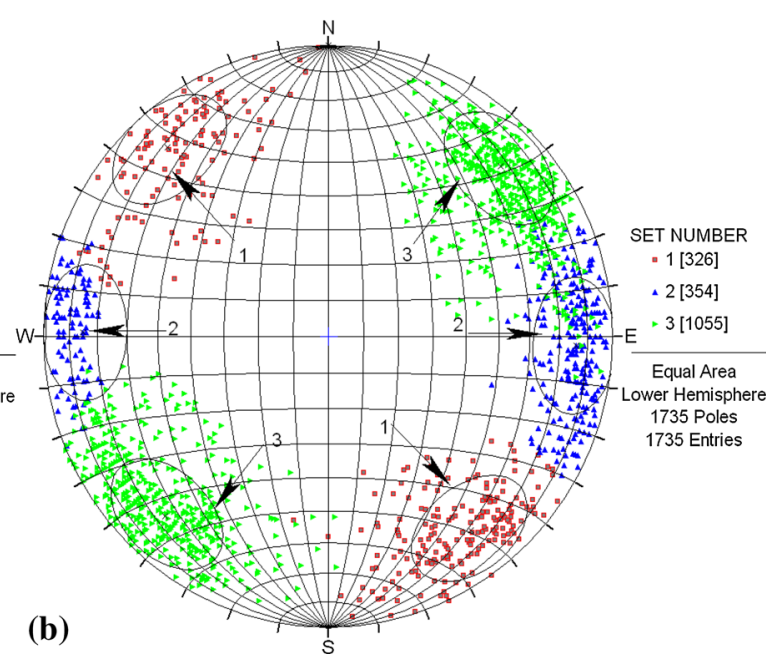

Fig. 6 Results of dominant discontinuity sets in Beishan. a Homogeneity I containing areas of CDERSPQN. b Homogeneity II containing areas of $\mathrm{GH}$

There are often a few "random points" left after discontinuity sets identification, which are usually difficult to uniquely determine the membership relations, namely the probabilities that this point belongs to different sets are nearly identical. If the sets are divided merely based on fuzzy variable values, it is not only difficult to distinguish the boundary of each set, but also easy to interfere the calculation accuracy of center vector of a set. Therefore, based on the measured orientation data of Beishan, "random points" were screened out by improved fuzzy clustering algorithm and subsequently were used to conduct statistical analysis separately, and then dominant discontinuity sets in homogeneity I and II were identified using the fuzzy clustering method (Zhou et al. 2012), the results are shown in Fig. 6, dominant sets center orientation is listed in Table 3.

In Fig. 6, discontinuities with approximately equal dip angle and opposite dip directions are divided into the same joint set. The reason is that considering the orientation data is the major index when delineating joint sets, to fulfill the requirements of partitioning, sine of the angle between two joint normal vectors is adopted as the measurement of distance between two orientation data. Joint orientations with the above features (approximately, equal dip angles and opposite dip directions) have small sine values, which mean the distance between the two joint orientations is relatively small, thus they are put into the same set. 
Table 3 Statistics parameters of dominant discontinuity sets

\begin{tabular}{llllr}
\hline Homogeneity & $\begin{array}{l}\text { Dominant } \\
\text { set }\end{array}$ & \multicolumn{2}{l}{ Center orientations } & \multirow{2}{*}{$\begin{array}{l}\text { Fisher } \\
\text { constant }\end{array}$} \\
\cline { 3 - 4 } & & $\begin{array}{l}\text { Dip } \\
\text { direction }\left(^{\circ}\right)\end{array}$ & $\begin{array}{l}\text { Dip } \\
\text { angle }\left(^{\circ}\right)\end{array}$ \\
\hline I & Set1 & 49 & 81.2 & 10.85 \\
& Set2 & 116.7 & 72 & 1.59 \\
II & Set1 & 324.5 & 83 & 7.21 \\
& Set2 & 272.1 & 84 & 21.17 \\
& Set3 & 235.6 & 75.7 & 2.09 \\
\hline
\end{tabular}

Characteristic parameters statistics

The measured coordinate data of discontinuities were imported into the Arc-GIS software to reconstruct objective distributions of discontinuities (e.g., $\mathrm{P}$ and I in Fig. 7), Discontinuities located on the same slope side were picked out to carry out the best outcrop plane fitting. After projecting discontinuities to the fitted plane, probability distributions of parameters (e.g., trace length) in dominant sets were obtained by statistical analysis (processing procedure is shown in Fig. 8).

Based on the hypothesis of Baecher circular disk, the sampling bias correction was carried out, spacing, density and trace length statistical distribution were then obtained, the corresponding unknown parameters, such as disk diameter distributions were derived based on trace length probability distribution of discontinuities by using following classics equation (Warburton 1980):

$h_{A}(L)=\frac{L}{m} \int_{L}^{m} \frac{g(D) d D}{\sqrt{D^{2}-L^{2}}}$

The mathematical expectation $m$ can be obtained using the following equation:

$m=\int_{0}^{\infty} D g(D) d D$

where $D$ is the diameter of discontinuities, $L$ is the trace length of discontinuities, $m$ is mathematical expectation of diameter, $g(D)$ is the probability density function of diameters, $h_{A}(L)$ is the probability density function of trace length.

Mean volumetric frequency (mean 3D density) was derived based on mean areal frequency (mean 2D density) of discontinuities by using following equation (Kulatilake and $\mathrm{Wu}$ 1984):

$E\left(\lambda_{v}\right)=\frac{E\left(\lambda_{a}\right)}{E(D) E|\sin v|}$ where $D$ is the diameter of discontinuities, $E(D)$ is the mean diameter of discontinuities, $E\left(\lambda_{v}\right)$ is the mean volumetric frequency of discontinuities, $E\left(\lambda_{a}\right)$ is the mean areal frequency of discontinuities, Elsinvl is the sinusoidal of angle between discontinuities average direction and the sample surface direction of this set.

The calculation results of disk diameter and volumetric frequency are shown in Table 4 (taken homogeneity I as example). There is an inconsistency between probability density function (PDF) of measured trace length and that of theoretical diameter, which implies that trace length and diameter may not follow the same probability distribution. Therefore, it remains unclear whether or not trace length PDF could be used in the DFN simulation instead of true diameter PDF.

\section{Establishment of model}

Statistical values of spatial frequency are first obtained as input parameters. Pseudo random number is then generated using a Poisson distribution. This number is taken as the discontinuities number within a certain volume of the model. The following step is to simulate disk center position, diameter and orientation, using the same Poisson random number generation technique to generate the center coordinates of each disk in the model volume. The disk diameter and orientation are generated according to their respective probability distribution function by Monte-Carlo method. Ultimately, the disk size and orientation are determined. However, theoretically there are countless models generated according to the method mentioned above. To endow the results with more statistical meaning, each independent parameter was generated five times, and a total of 125 random models were obtained by means of permutation and combination. Homogeneity I is taken as an example. Discontinuities network is generated in three-dimensional space with size $36.5 \mathrm{~m} \times 25 \mathrm{~m} \times 30 \mathrm{~m}$. The sampling windows are used to calculate the average dip direction, the average dip angle, corrected trace length, spherical deviation, etc. After preliminary comparison among different realizations, a relatively satisfactory model is chosen and shown in Fig. 9 (data comparison process is described in detail below) Basic parameters of the model are listed in Table 5. This model is built up based on in situ measurement data, and for the purpose of clearly showing the exact position of measured discontinuities, a plane with specific slope representing true outcrop and intersect traces are also plotted in corresponding position in this more objective model. 

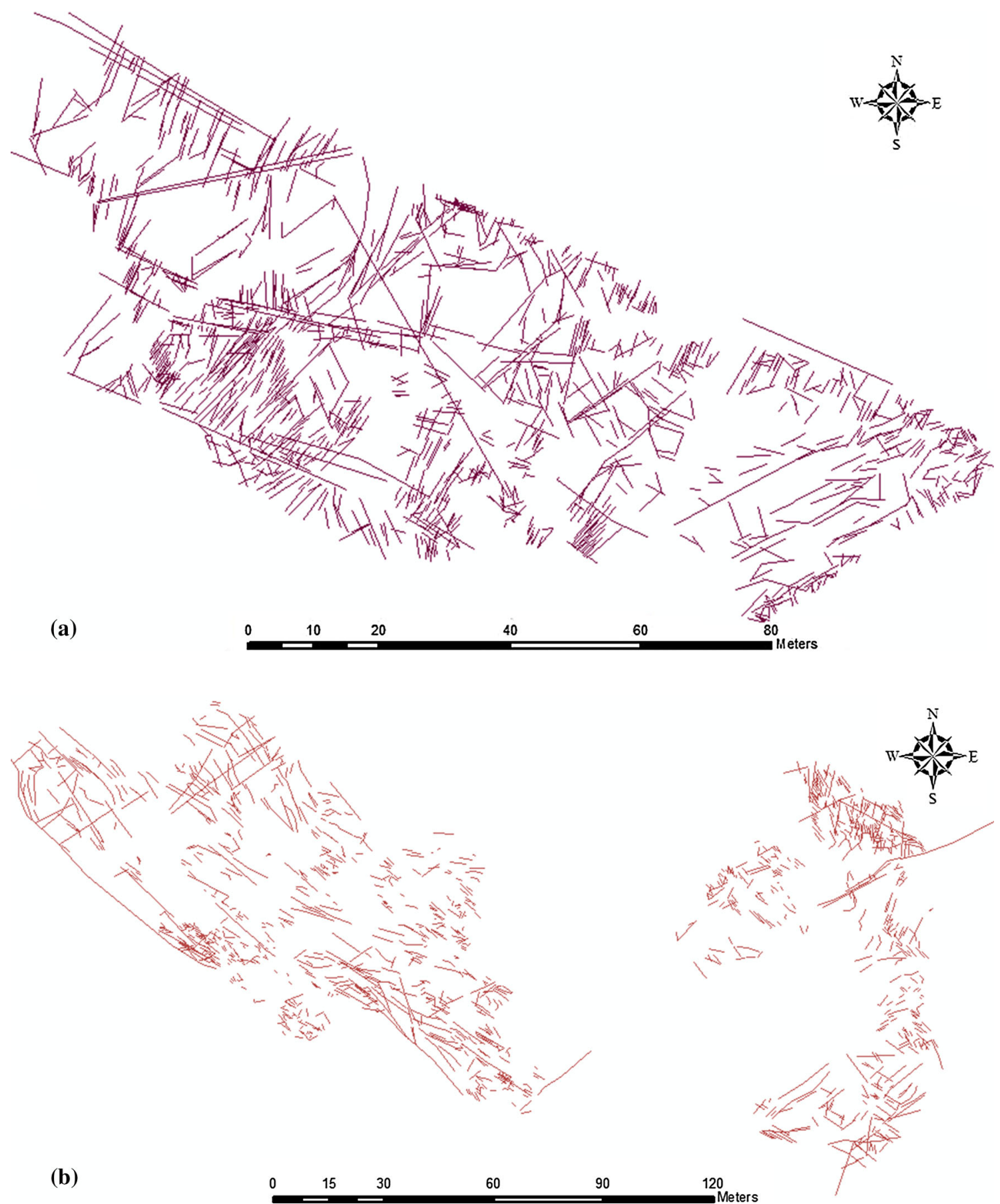

(b)

$\begin{array}{llll}0 & 15 & 30 & 60\end{array}$

60

90

Meters

Fig. 7 Trace maps of discontinuities in Jijicao block, Beishan. a Area P. b Area I

\section{Validity}

Figure test

Validity tests of the stochastic model mainly consist of figure test and numerical test. Figure test makes visual comparison between traces formed by the stochastic model intersected with sample window (or virtual outcrop surface) with those measured through in situ sampling window. Reliability of the model can therefore be estimated through visual observation. Figure 10 shows a test example of the aforementioned model: (a) is the traces of real discontinuities within the sampling window in simulated domain; (b) is the traces of the stochastic model cut by the sampling window. For the purpose of direct comparison of results, the sampling window used in the simulation is the same as the observation window on real outcrop slope in in situ discontinuities measurement 


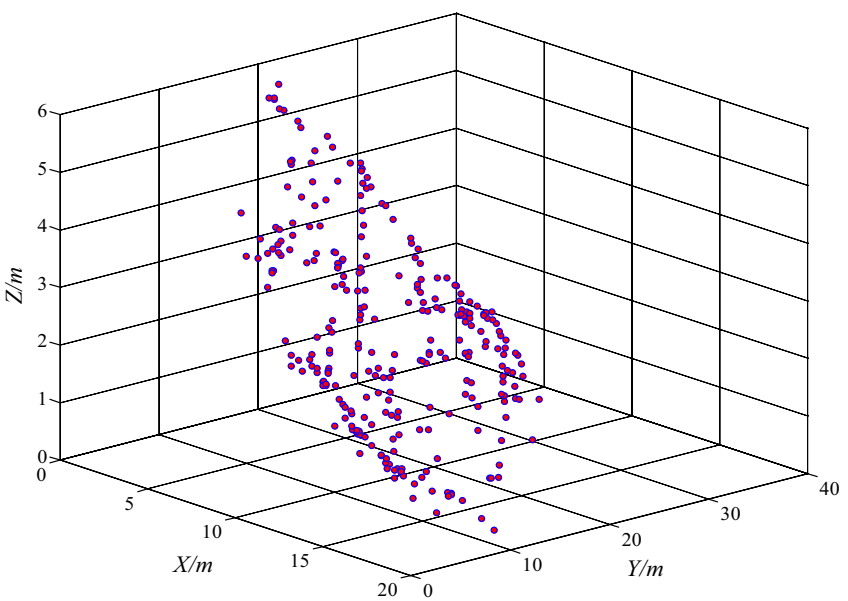

(a)

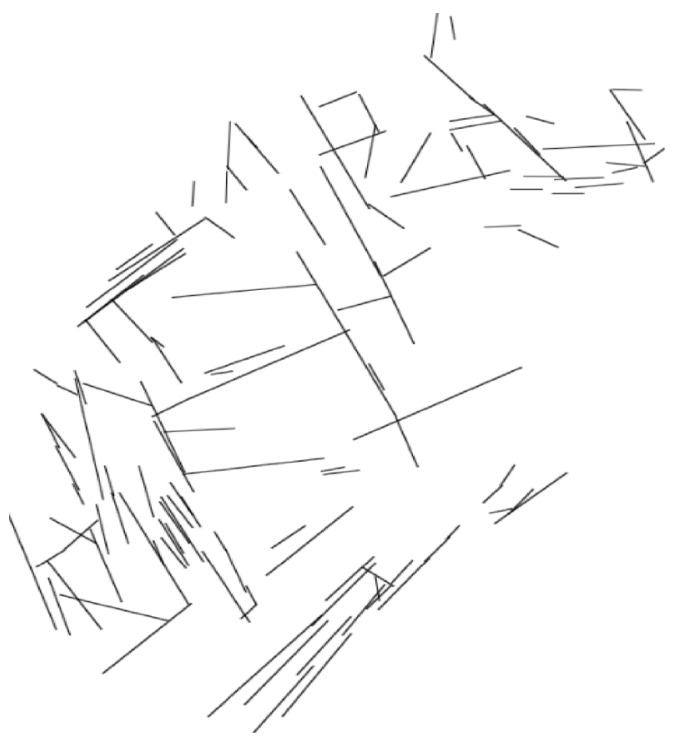

(c)

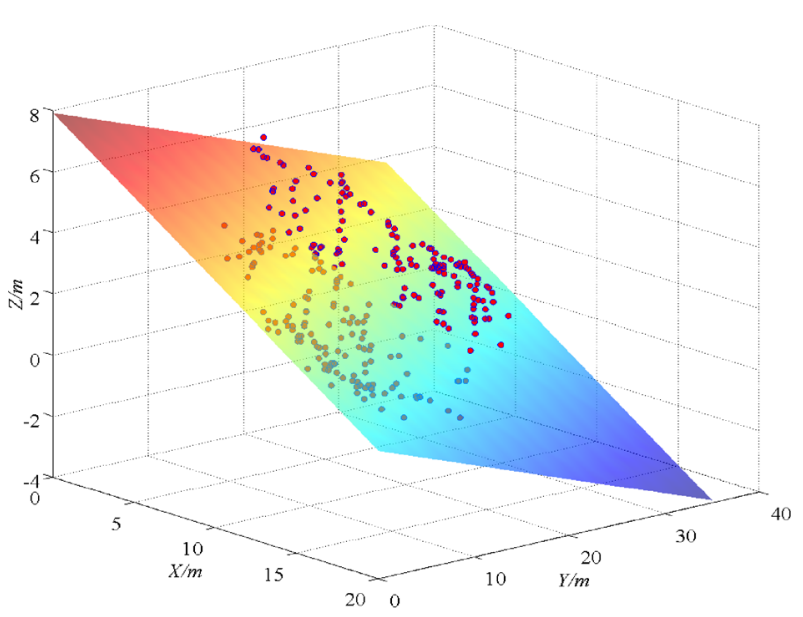

(b)

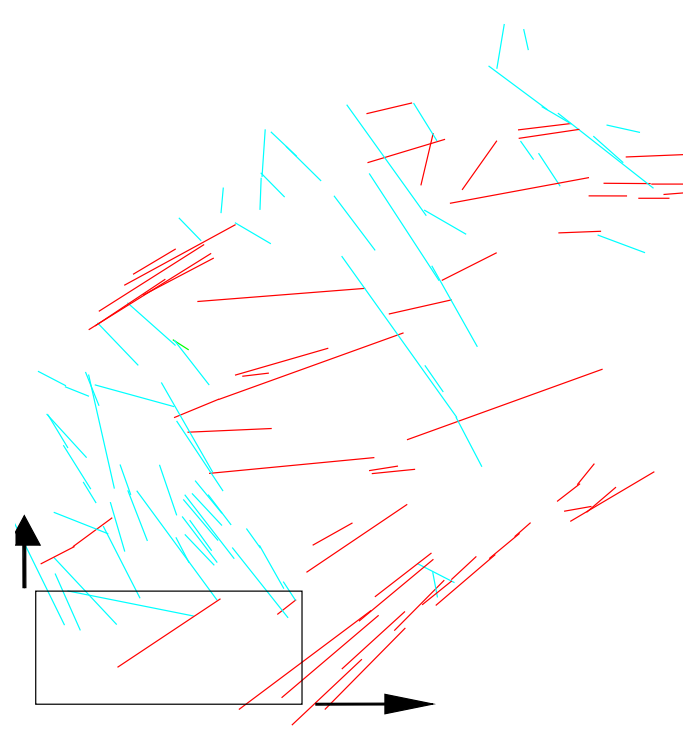

(d)

Fig. 8 Discontinuities digitalization processing procedure. a Select discontinuities on the same slope side of outcrop. b Best outcrop plane fitting. c Discontinuities projection. d Parameters statistics

Table 4 Statistics parameters of discontinuities in homogeneity I

\begin{tabular}{|c|c|c|c|c|c|c|}
\hline \multirow[t]{2}{*}{ Dominant sets } & \multicolumn{3}{|l|}{ Diameter } & \multicolumn{2}{|l|}{ Areal frequency } & \multirow{2}{*}{$\begin{array}{l}\text { Volumetric frequency } \\
\text { Mean (amount } \mathrm{m}^{-3} \text { ) }\end{array}$} \\
\hline & Distribution type & Mean (m) & Variance $\left(\mathrm{m}^{2}\right)$ & Related parameters & Mean (amount $\mathrm{m}^{-2}$ ) & \\
\hline Set1 & Lognormal & 2.71 & 0.27 & $\lambda=27.78$ & 0.015 & 0.028 \\
\hline Set2 & Lognormal & 2.78 & 0.185 & $\lambda=20.41$ & 0.017 & 0.031 \\
\hline
\end{tabular}

(shown in Fig. 9, specific parameters are shown in Table 5).

Direct visual comparison of Fig. 10a with $b$ shows that the stochastic model possesses relatively high similarity with the actual situation with respect to the discontinuities number, orientation and trace length characteristics (quantitative index derived from numerical tests are shown in next section). This figure test suggests the preliminary validity of the stochastic model. 

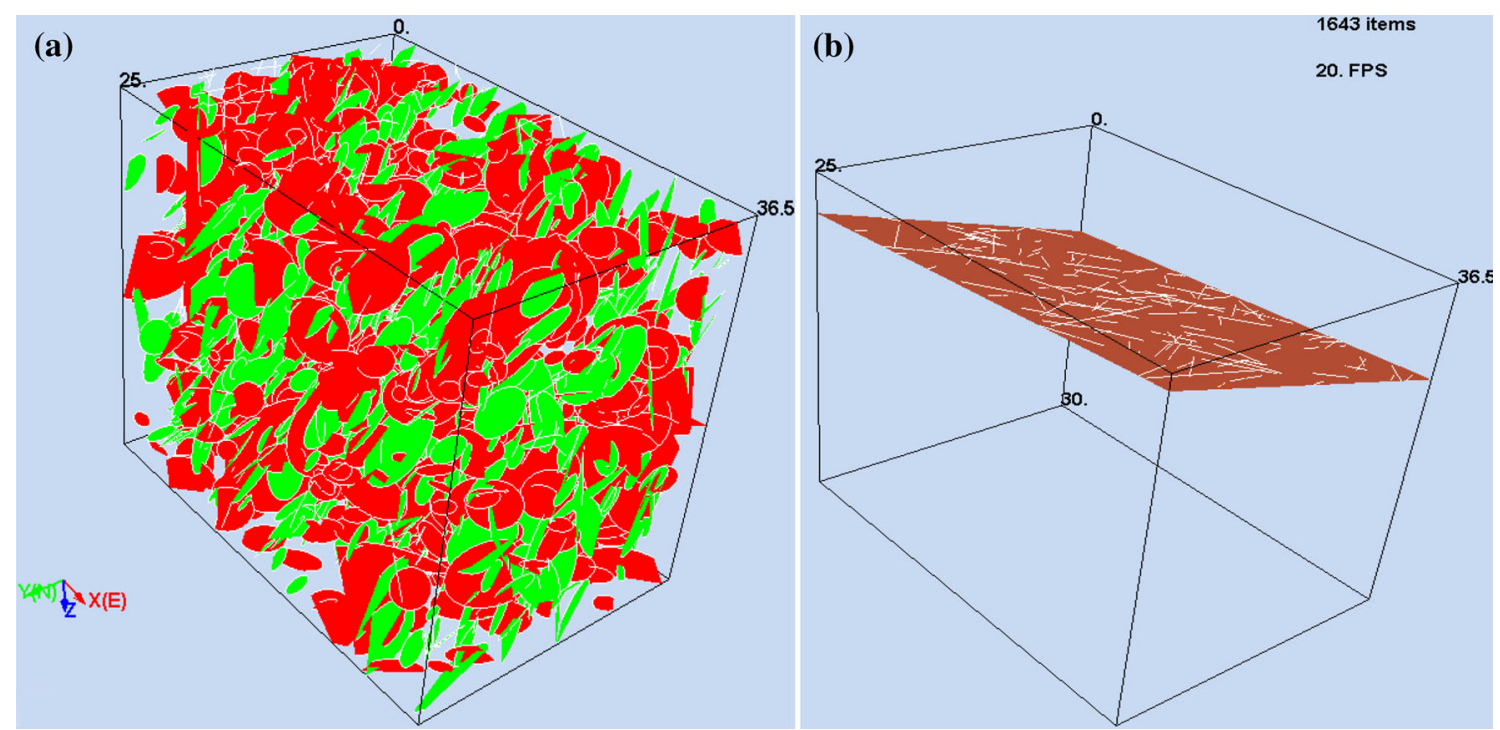

Fig. 9 Results of stochastic simulations for homogeneity I. a Stochastic model including two dominant sets: set 1 and 2 are marked by red and green, respectively. b A plane which is a simulation of real outcrop, on which intersected traces are plotted in corresponding position

Table 5 Parameters of stochastic model in homogeneity I

\begin{tabular}{llllll}
\hline $\begin{array}{l}\text { Set } \\
\text { number }\end{array}$ & $\begin{array}{l}\text { Truncation } \\
\text { value }(\mathrm{m})\end{array}$ & $\begin{array}{l}\text { Fracture } \\
\text { number } \\
\text { (amount) }\end{array}$ & $\begin{array}{l}\text { Sampling window } \\
\text { orientation }\end{array}$ & $\begin{array}{l}\text { Number of } \\
\text { traces } \\
\text { (amount) }\end{array}$ \\
\cline { 4 - 5 } & & $\begin{array}{l}\text { Dip } \\
\text { direction } \\
\left({ }^{\circ}\right)\end{array}$ & $\begin{array}{l}\text { Dip } \\
\text { angle } \\
\left({ }^{\circ}\right)\end{array}$ & \\
\hline 1 & 0.5 & 750 & 12.6 & 15.9 & 54 \\
2 & 0.5 & 893 & 12.6 & 15.9 & 80 \\
\hline
\end{tabular}

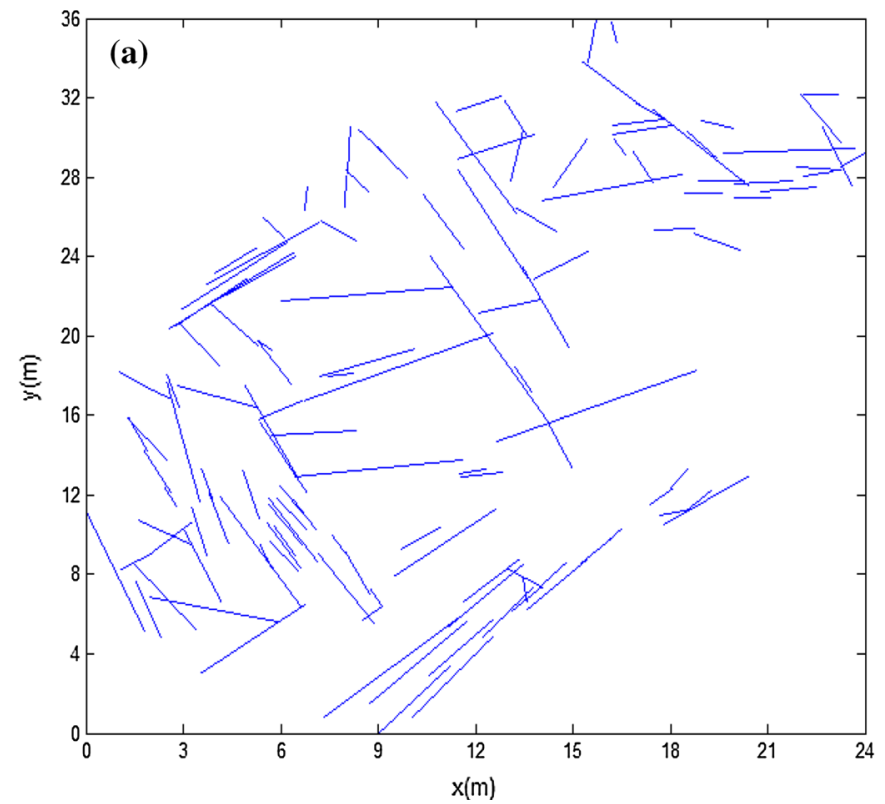

\section{Numerical test}

The graphical inspection result above only obtains a qualitative judgment that the model is relatively effective, further numerical tests are needed to derive quantitative index for the characterization of validation degree. In numerical tests data from stochastic model are collected after statistical analysis and are compared with the measured data. Data comparison should follow certain

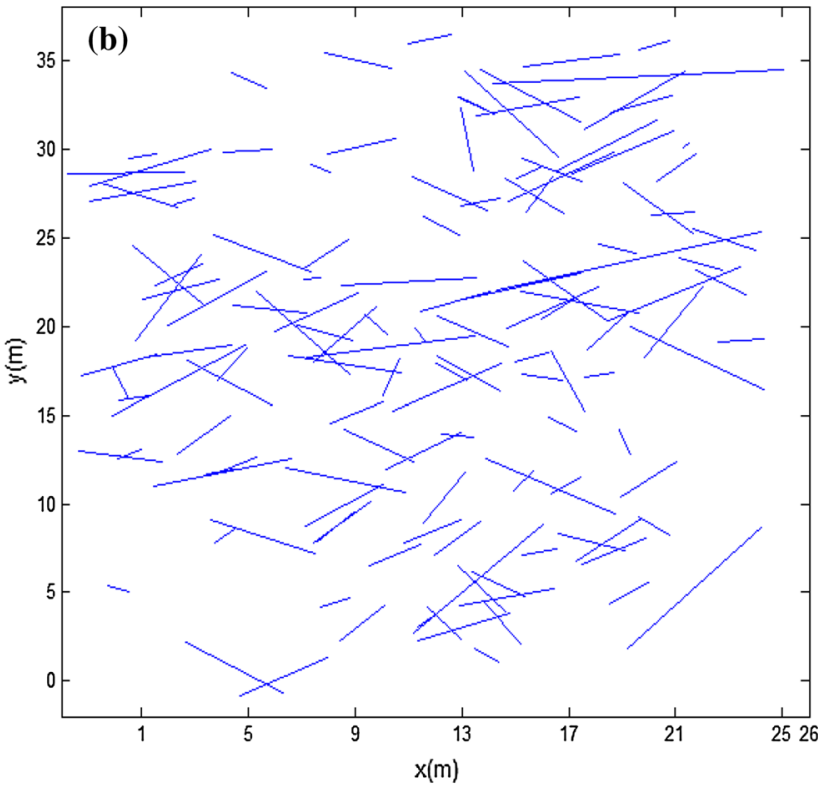

Fig. 10 Comparison between measured traces and numerical model. a In-situ measured discontinuities traces. b Simulated traces formed by intersection between sampling window and stochastic model 
Table 6 Results of comparison between numerical model data and in situ measured data on sampling window

\begin{tabular}{|c|c|c|c|c|c|c|c|c|}
\hline \multirow{2}{*}{$\begin{array}{l}\text { Set } \\
\text { number }\end{array}$} & \multicolumn{2}{|c|}{ Discontinuity trace } & \multicolumn{3}{|c|}{ Corrected trace length } & \multicolumn{3}{|l|}{ Orientation } \\
\hline & Number & $\begin{array}{l}\text { Difference } \\
\text { ratio }(\%)\end{array}$ & $\begin{array}{l}\text { Mean } \\
(m)\end{array}$ & $\begin{array}{l}\text { Difference } \\
\text { ratio }(\%)\end{array}$ & $\begin{array}{l}\text { Variation } \\
\text { coefficient }(\%)\end{array}$ & $\begin{array}{l}\text { Average dip } \\
\text { direction }\left({ }^{\circ}\right)\end{array}$ & $\begin{array}{l}\text { Average dip } \\
\text { angle }\left(^{\circ}\right)\end{array}$ & $\begin{array}{l}\text { Spherical } \\
\text { deviation }\end{array}$ \\
\hline \multicolumn{9}{|l|}{1} \\
\hline Model & 54 & 6.9 & 3.07 & 11.48 & 21.73 & 52.82 & 76.56 & 0.11 \\
\hline Original & 57 & & 2.76 & & 24.27 & 49 & 81.2 & 0.03 \\
\hline \multicolumn{9}{|l|}{2} \\
\hline Model & 80 & 5.26 & 2.90 & 2.84 & 19.24 & 116.55 & 70.31 & 0.22 \\
\hline Original & 75 & & 2.82 & & 28.01 & 116.7 & 72 & 0.04 \\
\hline
\end{tabular}

Table 7 Results of comparison between numerical model data and in-site statistical data in three-dimensional space

\begin{tabular}{|c|c|c|c|c|c|c|c|c|}
\hline \multirow{2}{*}{$\begin{array}{l}\text { Set } \\
\text { number }\end{array}$} & \multicolumn{2}{|c|}{ Discontinuity } & \multicolumn{3}{|c|}{ Diameter } & \multicolumn{3}{|l|}{ Orientation } \\
\hline & Number & $\begin{array}{l}\text { Difference } \\
\text { ratio }(\%)\end{array}$ & $\begin{array}{l}\text { Mean } \\
(\mathrm{m})\end{array}$ & $\begin{array}{l}\text { Difference } \\
\text { ratio }(\%)\end{array}$ & $\begin{array}{l}\text { Variation } \\
\text { coefficient }(\%)\end{array}$ & $\begin{array}{l}\text { Average dip } \\
\text { direction }\left(^{\circ}\right)\end{array}$ & $\begin{array}{l}\text { Average dip } \\
\text { angle }\left(^{\circ}\right)\end{array}$ & $\begin{array}{l}\text { Spherical } \\
\text { deviation }\end{array}$ \\
\hline \multicolumn{9}{|l|}{1} \\
\hline Model & 750 & 2.08 & 3.02 & 11.3 & 20.5 & 50.6 & 73.4 & 0.12 \\
\hline Original & 766 & & 2.71 & & 19.2 & 51.3 & 76.8 & 0.14 \\
\hline \multicolumn{9}{|l|}{2} \\
\hline Model & 893 & 5.30 & 3.20 & 15.2 & 17.4 & 115.9 & 68.7 & 0.36 \\
\hline Original & 848 & & 2.78 & & 15.5 & 118.3 & 70.4 & 0.16 \\
\hline
\end{tabular}

principles. In this paper, normalized relative error and coefficient of variation are adopted to implement quantitative comparison. Normalized relative error is the percentage of relative error of model data with respect to the original data, using the following expression (Wang et al. 2004):

$\eta=\left|\frac{M-T}{T}\right| \times 100 \%$

where $\eta$ is the normalized relative error, $M$ is the mean of model data, $T$ is the mean of the original data.

The definition above shows that the smaller $\eta$ value is, the more similar the two groups of data are. When $\eta$ is less than $30 \%$, the model data are usually considered in good agreement with the measured data. Coefficient of variation is defined as the ratio between standard deviation and mean value, using the following expression (Wang et al. 2004):

$\operatorname{cov}=\frac{\sigma}{\mu} \times 100 \%$

where cov is the level of uncertainty of parameters or model, $\sigma$ is the standard deviation, $\mu$ is the mean value.

If cov is more than $30 \%$, variation of data in the group is considered to be big while the confidence level is low. In addition, discontinuities orientation elements (dip direction, dip) are related to each other in stochastic simulation, they should not be treated separately. The following equation (Wang et al. 2004) can be used to evaluate the type of spherical deviation with respect to each orientation data:

$\zeta=\sqrt{1-\frac{|R|}{N}}$

$|R|=\left[\left(\sum_{i=1}^{N} l_{i}^{2}\right)+\left(\sum_{i=1}^{N} m_{i}^{2}\right)+\left(\sum_{i=1}^{N} n_{i}^{2}\right)\right]^{1 / 2}$

where $\zeta$ is the spherical deviation of orientation data, $l_{i}, m_{i}, n_{i}$ is the ith Cartesian coordinate component of discontinuities normal vector, $N$ is the discontinuities number of each set.

It is generally accepted that the fact that $\zeta$ larger than 0.25 suggests a less concentrated and statistically insignificant orientation data set.

The quantitative index derived from numerical tests of Fig. 10 shows that normalized relative error less than $7 \%$ with respect to discontinuities number, spherical deviation less than 0.25 with respect to orientation, normalized relative error less than $11.48 \%$ with respect to trace length.

Numerical tests are carried out for the model on the sampling window; the results are listed in Table 6. 
All the data of the model to be validated are gathered and analysed, the overall effectiveness test results are listed in Table 7.

According to the results listed in Tables 6 and 7, this stochastic model is capable of fulfilling the requirement of statistical testing, both in terms of the sampling window inspection and the statistical results involving the whole data. The maximum difference ratio is $15.20 \%$, the maximum variation coefficient is $28.01 \%$ and the maximum spherical deviation is 0.22 (Simulation result of set 2 is out of range, which may result from the more significant accumulated error induced by the largest quantity of stochastic discontinuities of this set in the whole model), most of which are within their respective threshold ranges, thus indicate that this stochastic model in the specific condition is with relatively high reliability, therefore, it can better meet the need of practical engineering application, and the mechanical calculation and seepage simulation results based on this model possess high accuracy and theoretical reliability.

\section{Conclusions}

Our group has embarked on an integrated research program, whose main goal is to build up a proper stochastic discontinuity network model for Jijicao block (Beishan of Gansu province), one of the main candidate sites for the Chinese HLW repository. In the present paper, methods of data measurement, digitalization and model establishment procedure are described in detail. Reliability of the model was verified graphically and numerically. Validation results suggest that an improvement of feasibility and effectiveness of the model was achieved. The proposed methods provide a new way for the stochastic discontinuity network simulation. Important conclusions are listed as follows:

(i) Significant bias may be induced if bias correction processes are neglected. Orientation frequency bias correction should be conducted when the dip angle of the discontinuity is relatively small, usually less than 20 degrees.

(ii) Based on in situ measurement data, two homogeneities are identified in Jijicao block, the dominant sets with respect to each homogeneity are also divided (two sets in homogeneity I, three sets in homogeneity II), and finally three-dimensional DFN models are established for both homogeneities.

(iii) Statistical results of measured data show that two dominant sets can be identified in homogeneity I of Jijicao block. The optimal diameter probability distributions of both sets are lognormal. (iv) Numerical validations both in terms of the sampling window inspection and the statistical results involving the whole data set demonstrate that the generated model is capable of representing in situ fracture features in a practical point of view. Take homogeneity I as example, compared to measured data, the maximum difference ratio of this model is $15.20 \%$, the maximum variation coefficient is $28.01 \%$ and the maximum spherical deviation is 0.22 . Mechanical calculation and seepage simulation results based on this model possess relatively high accuracy and theoretical reliability.

Acknowledgments This study was financially supported by the National Basic Research Program of China (973 Program, No.2013CB036001), and National Defense Key Program (No.[2012]491), and Colleges and Universities in Jiangsu Province plans to graduate research and innovation (No.CXZZ13_0057). The support received for this project from the Beijing Research Institute of Uranium Geology is appreciated very much.

Open Access This article is distributed under the terms of the Creative Commons Attribution License which permits any use, distribution, and reproduction in any medium, provided the original author(s) and the source are credited.

\section{References}

Baecher G (1983) Statistical analysis of rock mass fracturing. Math Geol 15(2):329-347

Chen JP (2001) 3-D network numerical modeling technique for random discontinuities of rock mass. Chin J Geotech Eng 23(4):397-402

Chen JP, Xiao SF, Wang Q (1995) Numerical modeling principle for random discontinuities 3-D network of rock mass. Northeast Normal University Press, Changchun

Cruden D (1977) Describing the size of discontinuities. Int J Rock Mech Min Sci Geomech Abstr 14:133-137

Dershowitz W, Einstein H (1988) Characterizing rock joint geometry with joint system model. Rock Mech Rock Eng 21(1):21-51

Einstein H, Baecher G (1983) Probabilistic and statistical methods in engineering geology. Rock Mech Rock Eng 16:39-72

Einstein H, Veneziano D, Baecher G (1983) The effect of discontinuity persistence on rock slope stability. Int J Rock Mech Min Sci Geomech Abstr 20(5):227-236

Guo L, Li XZ, Wang YZ, Chen WP, Cheng ML, Zhou YY (2013) Applicability research on structural homogeneity delineation of rock masses. Rock Soil Mech 34(10):2928-2937

Hammah R, Curran J (1998) Fuzzy cluser algorithm for the automatic identification of joint sets. Int $\mathrm{J}$ Rock Mech Min Sci 35(7):889-905

Huang Y, Zhou ZF, Wang JG, Dou Z (2014) Simulation of groundwater flow in fractured rocks using a coupled model based on the method domain decomposition. Environ Earth Sci 72:2765-2777

Jia HB, Ma SZ, Tang HM, Liu YR (2002) Study on engineering application of 3-D modeling of rock discontinuity network. Chin J Rock Mech Eng 21(7):976-979

Kiraly L (1969) Statistical analysis of fracture (orientation and density). Geol Rundsch 59(1):125-151 
Kissinger A, Helmig R, Ebigbo A, Class H, Lange T, Sauter M, Heitfeld M, Klünker J, Jahnke W (2013) Hydraulic fracturing in unconventional gas reservoirs: risks in the geological system, part 2. Modelling the transport of fracturing fluids, brine and methane. Environ Earth Sci 70:3855-3873

Koike K, Liu C, Sanga T (2011) Incorporation of fracture directions into 3D geostatistical methods for a rock fracture system. Environ Earth Sci 66(5):1403-1414

Kulatilake P (1985) Fitting fisher distributions to discontinuity orientation data. J Geol Educ 33:266-269

Kulatilake P, Wathugala D (1990) Three dimensional fracture network modeling and verification. In: International conference on mechanics of jointed and faulted rock, Vienna, Austria, pp 71-82

Kulatilake P, Wu T (1984) The density of discontinuity traces in sampling windows. Int J Rock Mech Min Sci Geomech Abstr 21(6):345-347

Kulatilake P, Wathugala D, Stephansson O (1993) Joint network modeling with a validation exercise in stripa mine, Sweden. Int J Rock Mech Sci Geomech Abstr 30(5):503-526

Kulatilake P, Chen JP, Teng J, Xiao SF, Pan G (1996) Discontinuity geometry characterization in a tunnel close to the proposed permanent shiplock area of the three gorges dam site in China. Int J Rock Mech Min Sci Geomech Abstr 33(3):255-277

Lei HN, Yuan SG (1989) Structural models of joint rock mass. JIN SHU KUANG SHAN 8:22-24

Li XZ, Zhou YY, Wang ZT, Zhang YS, Guo L, Wang YZ (2011) Effects of measurement range on estimation of trace length of discontinuities. Chin J Rock Mech Eng 30(10):2049-2056

Li XZ, Guo L, Zhang YS, Suo PS, Zhou YY, Wang YZ (2014) Statistical homogeneity delineation of fractured rock mass. World Nucl Geosci 31(S1):184-190. doi:10.3969/j.issn.16720636.2014.S1.010

Mahtab M, Yegulap T (1984) A similarity test for grouping orientation data in rock mechanics. In: 25 th $\mathrm{U}$. S. symposium on rock mechanics, pp 495-502

Miller SM (1983) A Statistical method to evaluate homogeneity of structural populations. Math Geol 15(2):317-328

Müller C, Siegesmund S, Blum P (2010) Evaluation of the representative elementary volume (REV) of fractured geothermal sandstone reservoir. Environ Earth Sci 61:1713-1724

Oda M (1980) A statistical study of fabric in random assembly of spherical granules. In: Earthquake Research and Engineering Laboratory, Technical Report, pp 804-29

Oda M (1982) Fabric tensor for discontinuous geological materials. Soils Found 22(4):96-108

Pahl P (1981) Estimating the mean length of discontinuity trace. Int J Rock Mech Min Sci Geomech Abstr 18:221-228
Priest S (1993) Discontinuity analysis for rock engineering. Springer, Berlin

Priest S, Hudson J (1981) Estimation of discontinuity spacing and trace length using scan line surveys. Int J Rock Mech Min Sci Geomech Abstr 18:183-197

Robinson P (1983) Connectivity of fracture systems-a percolation theory approach. J Phys A Math Gen 16:605-614

Sen Z, Kazi A (1984) Discontinuity spacing and RQD estimates from finite length scan lines. Int J Rock Mech Min Sci Geomech Abstr 21(4):203-212

Shanley R, Mahtab M (1976) Delineation and analysis of clusters in orientation data. Math Geol 8(1):9-23

Snow D (1970) The frequency and apertures of fracture in rock. Int J Rock Mech Min Sci Geomech Abstr 7:23-40

Tenzer H, Park C, Kolditz O, McDermott CI (2010) Application of the geomechanical facies approach and comparison of exploration and evaluation methods used at Soultz-sous-Forts (France) and Spa Urach (Germany) geothermal sites. Environ Earth Sci 61(4):853-880

Terzaghi R (1965) Sources of error in joint surveys. Geotechnique 15(3):287-304

Wang SL, Chen JP, Shi B (2004) Verification of random 3-D fractures network model of rock mass. J Eng Geol 12(2):177-181

Warburton P (1980) A stereological interpretation of joint trace data. Int J Rock Mech Min Sci Geomech Abstr 17(4):181-190

Watkins M (1971) Terminology for describing the spacing of discontinuities of rock masses. Q J Eng Geol 3:193-195

Watson G, Irving E (1957) Statistical methods in rock magnetism. In: Royal Astronomy Society monthly notices, Geophysics Supp 7, pp 289-300

$\mathrm{Xu}$ JX (1992) 3-D Modeling of rock discontinuity network and fragment-size calculation for rock mass. In: The second national youth symposium on engineering geological mechanics proceedings, pp 56-77

$\mathrm{Xu}$ CS, Peter D (2010) A new computer code for discrete fracture network modeling. Comput Geosci 36(3):292-301

Zhou YY (2013) Research on statistical parameters of rock mass fracture system in high-level radioactive waste repository Beishan candidate site. Master dissertation, Nanjing Uiversity, Nanjing

Zhou YY, Li XZ, Guo L (2012) Delineation of major joint sets for Gansu Beishan area. In: The 12th national symposium proceedings on Rock Mechanics and Engineering

Zhu WB (1992) The studies of joint network simulation and their preliminary applications. Min Metall Eng 12(8):1-4 